Human \& Animal Health

Vol.59: e16150622, January-December 2016 http://dx.doi.org/10.1590/1678-4324-2016150622 ISSN 1678-4324 Online Edition

\title{
Regulating Effect Of Carnosine And /Or L- Arginine On The Expression Of Inflammatory Molecules Induced Nephropathy In The Hypoxic Rat Model
}

\author{
Nouf M. Al-Rasheed ${ }^{1}$, Laila Fadda ${ }^{1}$, Azza M Mohamed ${ }^{* 2,3}$, Hala A. Attia ${ }^{1,4}$, Nawal \\ M. Al-Rasheed ${ }^{1}$ \\ ${ }^{1}$ Department of Pharmacology and Toxicology, College of Pharmacy, King Saud University, Riyadh, \\ Kingdom of Saudi Arabia. ${ }^{2}$ Biochemistry Department, Faculty of Science - Al Faisaliah, King Abdulaziz \\ University, Jeddah, Saudi Arabia. ${ }^{3}$ Theraputic Chemistry Department, National Research Center, Dokki, \\ Egypt. ${ }^{4}$ Department of Biochemistry, College of Pharmacy, Mansoura Univrsity, Mansoura, Egypt.
}

\begin{abstract}
This study aimed to explore the effective role of carnosine and /or L-arginine in down regulation of the inflammatory molecule expression caused renal damage in response to sodium nitrite (NaNO2) induced hypoxia in rats. NaNO2 was administered subcutaneously (s.c.) to rats as a single dose (60 $\mathrm{mg} / \mathrm{kg}$ body weight ). L-arginine (200mg/Kg body weight) and carnosine $(250 \mathrm{mg} / \mathrm{Kg}$ body weight $)$ were administered (i.p.) as a single dose, 24 h before NaNO2 injection. The results revealed that preadministration of arginine and /or carnosine to NaNO2 hypoxic rats, significantly modulated the increases in serum markers of renal function (creatinine and urea) as well as the decrease in hemoglobin (Hb) level versus hypoxic rats. The two agents each alone or in a combination, markedly down regulated the serum pro-inflammatory molecules, including tumor necrosis factor- $\alpha(T N F-\alpha), C$ reactive protein (CRP), vascular endothelial growth factor (VEGF) and heat shock protein -70 (HSP-70) as well as interleukin-6 (IL-6) in renal tissue compared to NaNO2 hypoxic rats. Also, the two agents successfully down modulated the alteration in the serum hypoxia inducible factor $1 \alpha(H I F 1 \alpha)$. The present biochemical results were also supported by histopathological examination. In conclusion, the current data revealed that although the efficacy of arginine or carnosine each alone, their combination was more effective in ameliorating the renal damage induced by inflammatory molecules in response to NaNO2 hypoxia. This may support the use of this combination as an effective drug to treat hypoxic renal damage
\end{abstract}

Key words: hypoxia, arginine, carnosine , inflammatory molecules, renal damage

\footnotetext{
*Author for correspondence: azzamohamed99@yahoo.com
}

Braz. Arch. Biol. Technol. v.59: e16150622 Jan/Dec 2016 


\section{INTRODUCTION}

Oxygen homeostasis is critical for many physiological and developmental processes, and, its disturbances have key roles in the pathogenesis of many human diseases, including renal disease ( Semenza 2011). Chronic renal disease (CRD) is an important risk factor causing mortality (Go et al. 2004). There are various causes for the CRD, represented by interstitial fibrosis, glomerular sclerosis, and nephron destruction (Remuzzi and Bertani 1998). ). The kidney is sensitive to oxygen supply. Increasing evidence indicated that a reduction in renal oxygen tensions plays an important role in the progression of chronic renal disease (Eckardt et al. 2005). The kidney needs a complicated vasculature to maintain its architecture and function and is thus highly susceptible to hypoxic insults. Hpoxia causes a a rapid decline in capillary density which provides the structural basis for adequate oxygen delivery to tubular cells. Also low oxygen tensions impairs energy generation and induces a proinflammatory state via the expression of certain pro-inflammatory gene products in the endothelium, such as leukocyte adhesion molecules and proinflammatory cytokines, leading to the end-stage feature in CRS (Bohle et al. 1996; Eckardt et al. 2005; Basuroy et al. 2006). Some authors reported that hypoxia is a potential cause of tissue inflammation through activation of nuclear factor $\kappa \mathrm{B}(\mathrm{NF} \kappa \mathrm{B})$, in the tissue macrophages (Rius et al. 2008) .

Sodium nitrite (NaNO2) is an inorganic salt used as a food additives and can be found in drinking water ( Fewtrell 2004; Habermeyer et al. 2015). The salt is one of the toxic agents that induces hypoxic organ damage and failure. The hazardous effect of $\mathrm{NaNO} 2$ is derived from the reaction of nitrite with amines and amides in food to produce nitrosamines and nitrosamides, respectively, which play vital roles in posing toxic effects in different organs (Tong et al. 2010; El-Sheikh and Khalil 2011). NaNO2 is highly reactive with hemoglobin causing methemoglobinemia, a condition in which there is a reduction in hemoglobin stability to transport oxygen leading to hypoxia (Craun et al. 1981). The administration of sodium nitrite causes dysregulation of inflammation, hypoxia, ischemia, oxidative stress and impaired energy metabolism which finally aggravate organ damage , including renal damage (El-Sheikh and Khalil 2011; Salama et al. 2013; Abu Aita and Mohammed 2014; Al-Gayyar et al. 2014; 2015).

Previous studies have shown that many antioxidant compounds are able to reduce the inflammatory reactions, thereby reducing the risk of tissue injury and organ dysfunction (Ivanov et al. 2008, Tsai et al. 2010)

L-Arginine is a basic natural amino acid and has important roles in many metabolic pathways within the human body. It serves as a precursor for the synthesis of biologically important molecules, including proteins, polyamines, creatine, agmatin, proline and glutamate (Morris 2006). Larginine is an essential component of the urea cycle, the only pathway for ammonia elimination and detoxification. L-Arginine is the only substrate in the biosynthesis of NO that has diverse physiological roles, including neurotransmission, vasorelaxation, vasodilatation, and regulation of the immune system (Bogdan 2001; Gad 2010). NO within its physiological concentration, exerts protective antiapoptotic actions (DeNadai et al. 2000) . L-Arginine also has antioxidant and anti-inflammatory potential actions (Ivanov et al. 2008). It can attenuate the inflammatory reactions by suppressing the generation of inflammatory mediators 
such as inflammatory cytokines and Creactive protein, which play the major role in the progression of tissue damage and organ dysfunction (Wu et al. 2001). Arginine is essential for the biosynthesis of parliament that strongly involved in the enhancement of protein synthesis (Moinard et al. 2005) and may facilitate healing during inflammation (Chung et al. 1993). Larginine has been found to improve renal function (Klahr 1999).

Carnosine (beta-alanyl-L-histidine) is an endogenous synthesized dipeptide that is present in different human tissues, including the kidney (Kiliś-Pstrusińska 2012). Lcarnosine is known to possess antioxidant and anti-inflammatory properties (Tsai et al. 2010). It has free radical scavenging functions (Hartman et al. 1990), can suppress lipid peroxidation, promote the expression of antioxidant enzymes and inhibit the inflammatory cytokine generation (Tsai et al. 2010 ). It has a cardioprotective impact against hypoxia-induced expression of hypoxia inducible factor in cardiomyoblasts (Bharadwaj et al. 2002). It can reduce rat mortality exposed to brain ischemia (Stvolinsky et al. 2000) and protect against ischemia/ reperfusion -induced acute renal failure in rats (Fujii et al. 2003).

The aim of this study is to explore the effective role of the antioxidants , Larginine and/ or carnosine against the inflammatory reactions induced renal tissue damage in rats exposed to hypoxia.

\section{MATERIAL AND METHODS}

\section{Chemicals}

Carnosine , L- arginine and sodium nitrite used in this study were analytically pure products of Sigma- Aldrich Chemical Co., St. Louis, MO, United States. All other chemicals were of high analytical grade, product of Sigma and Merck companies. Sodium nitrite and carnosine were dissolved in normal saline, while, idebenone and arginine were suspended in $1 \%$ gum acacia in normal saline.

\section{Animals and treatments}

Fifty Wistar adult male albino rats weighing 170-200 $\mathrm{g}$ were used in this study. The rats were obtained from the Experimental Animal house, Faculty of Pharmacy, King Saud University, Saudi Arabia. Animals were housed in special clean cages, and maintained at standard conditions (12-h light/dark cycle, temperature ranging $20-22^{\circ} \mathrm{C}$ and $60 \%$ humidity). Rats were fed with standard rat pellet chow with free access to tap water ad libitum for one week before the experiment for acclimatization. The animal Experimental protocol was approved by the Experimental Animal Ethics Committee at King Saud University, Faculty of Pharmacy, Saudi Arabia. After one week acclimation, the rats were kept fasting over night before treatment and randomly divided into five groups, each of ten rats Group 1, served as control . Group 2 : NaNO2treated animals. Group 3 : NaNO2treated animals and pre-injected with arginine $(200 \mathrm{mg} / \mathrm{kg}$, i.p. Ali et al. 2012) Group 4: NaNO2-treated animals and intraperitoneally injected with carnosine (250mg/kg, Al-Rasheed et al. 2015)

Group 5: NaNO2-treated animals and intraperitoneally injected with a combination of arginine $(200 \mathrm{mg} / \mathrm{kg}$, i.p.) and carnosine $(250 \mathrm{mg} / \mathrm{kg}$, i.p.)

Hypoxia was induced in rats by $\mathrm{NaNO} 2$ (60 mg/kg,). NaNO2 was administered subcutaneously (s.c.) as a single dose .L- arginine and carnosine were administered intraperitoneally, $24 \mathrm{~h}$ before $\mathrm{NaNO} 2$ injection. After one hour of $\mathrm{NaNO} 2$ injection, the rats were sacrificed under ether anesthesia, then blood samples were collected and divided into two parts. One part was 
Al-Rasheed, NM et al.

collected into tubes containing heparin for hemoglobin determination. The other part was allowed to coagulate and centrifuged for serum separation and use for serum biochemical analysis . After blood collection, the kidneys were removed and placed overnight in phosphate-buffered $10 \%$ formalin for fixation and histopathological examination.

\section{Determination of $\mathbf{H b}$}

$\mathrm{Hb}$ was determined colorimetrically using Drabkin's reagent according to the method of Kjeldsberg (1993) .

\section{Biochemical serum analysis}

Blood urea nitrogen (BUN) and creatinine concentration in serum as renal function parameters were estimated using a commercial assay kit (Wako Pure Chemicals, Osaka, Japan).

IL-6 was measured using a high sensitive rat Enzyme-linked immunosorbent assay (ELISA) kit (IBL International $\mathrm{GmbH}$, Flughafenstr, Hamburg, Germany) following the instructions of the manufacturer. TNF- $\alpha$ was measured using the ELISA assay kit following the instructions supplied by the manufacturer (DuoSet kits; R\&D Systems, Minneapolis, MN, USA). C-reactive protein (CRP) was estimated by immunonephelometric (Dade Behring N Latex High Sensitivity CRPTM mono assay) on a Behring Nephelometer II analyzer. In this method, polystyrene beads coated with rat monoclonal antibodies bind to serum CRP forming aggregates. The intensity of the scattered light is directly proportional to CRP concentration. The level of VEGF was assayed by calorimetric, quantitative, sandwich ELISA (R\&D Systems, UK) at $492 \mathrm{~nm}$, following the manufacturer's instructions. VEGF content was estimated using a standard curve generated with specific standards provided by the manufacturer. For the quantitative determination of HSP70, a sandwich rat HSP 70 ELISA Kit was used (Kamiya Biomedical, Washington, USA). ELISA kit was used to measure serum level of HIF$1 \alpha$ (Cayman Chemical Co, Ann Arbor, Michigan, USA)

\section{Histopathological examination}

A small pieces of kidney were fixed by $10 \%$ formalin and then embedded into paraffin, sectioned for 5-6- $\mu \mathrm{m}$ thick, and mounted on the glass microscope slides using standard histopathological techniques. The sections were stained with hematoxylineosin and examined by light microscopy.

\section{Statistical analysis}

Data were analyzed by comparing values for different treatment groups with the values of individual controls. Results are expressed as mean \pm SD. Significant differences among values were analyzed using one-way analysis of variance (ANOVA) followed by Bonferroni's test post-ANOVA.

\section{RESULTS}

\section{Biochemical observations}

Figure 1 shows the effect of arginine and /or carnosine on serum levels of kidney function biomarkers (creatinine and urea ) in control and hypoxia experimental groups. Induction of hypoxia in rats caused pronounced increases in serum creatinine and urea compared with control animals $(P \leq 0.001)$, and the injection of arginine and /or carnosine, significantly $(P \leq 0.001)$ down-modulated the deviation in these markers compared with hypoxia group.

The protective effect of arginine and /or carnosine on blood $\mathrm{Hb}$ concentration in control and hypoxia experimental groups is shown in Figure 3. The result revealed that induction of hypoxia in rats caused a significant decrease in $\mathrm{Hb}$ compared with control group $(P \leq 0.001)$. Pre-treatment of hypoxic rats with arginine and /or 
carnosine markedly modulated the deviation in blood $\mathrm{Hb}$ versus hypoxia untreated animals.

The levels of some immunological proinflammatory biomarkers, including TNF- $\alpha$, IL- 6 and CRP in the serum of control and hypoxia rat groups are illustrated in Figure 4 . These biomarkers were dramatically elevated in the sera of hypoxic rats compared with the control group $(P \leq 0.001)$. Administration of arginine and /or carnosine before the induction of hypoxia , markedly inhibited the induced inflammatory mediators compared with hypoxic animals .

The levels of VEGF (angiogenic factor), HSP70 and HIF $1 \alpha$ (index of hypoxia) were significantly increased in the sera of hypoxic rats compared with the control animals (Fig.5, $\quad P \leq 0.001$ ). Preadministration of arginine and /or carnosine, markedly reduced the dramatic increases in these parameters compared with hypoxic, untreated animals $(P \leq 0.001)$. The synergestic pre- treatment of hypoxic animals with the combination of arginine and carnosine was more effective in modulating most of the studied parameters near the normal levels.

\section{Histo-pathological observations}

The results of the biochemical markers were supported by the histopathological examination of renal tissues (Fig. 2). This examination revealed that the hypoxia induced animals showed degeneration of many renal corpuscles and degeneration of the epithelia of the tubules. Foci of cellular infiltration was also observed. Pre administration of either arginine or carnosine showed marked improvement of the renal corpuscles and tubules with a marked decrease of the cellular infiltration. However, Kidney of rats treated with the combination of the two agents showed apparently normal histology of renal corpuscles and tubules with absence of cellular infiltration.
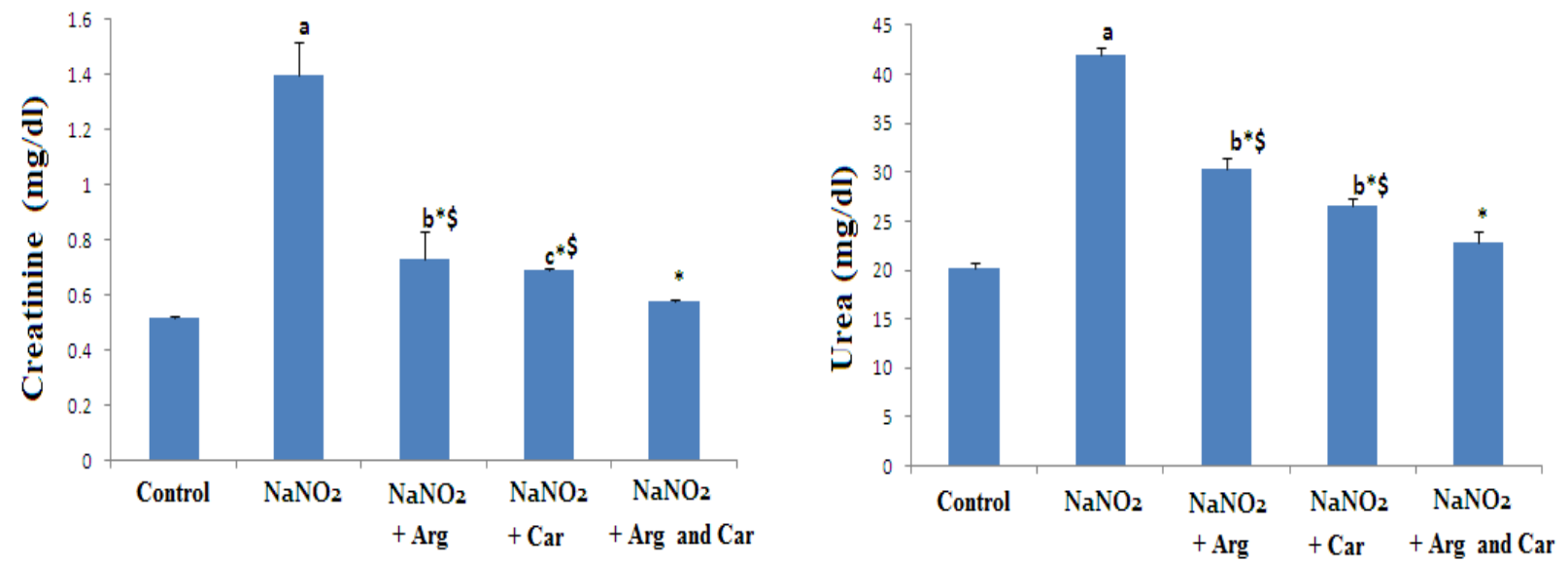

Figure 1- Effect of L-arginine (Arg) and/ or carnosine (Car) on serum kidney function markers ( creatinine and urea) in control and $\mathrm{NaNO} 2$ induced hypoxia groups. Data are expressed as means \pm S.D (n=10). ${ }^{a} P \leq 0.001,{ }^{b} P \leq 0.01,{ }^{c} P \leq 0.05$ compared with the control group, * $P \leq 0.001$, compared with NaNO2 induced hypoxia group, ${ }^{\$} P \leq 0.05$ compared with the combination group $(\mathrm{NaNO} 2+\mathrm{Arg}+$ Car), using ANOVA followed by Bonferroni as a post-ANOVA test 


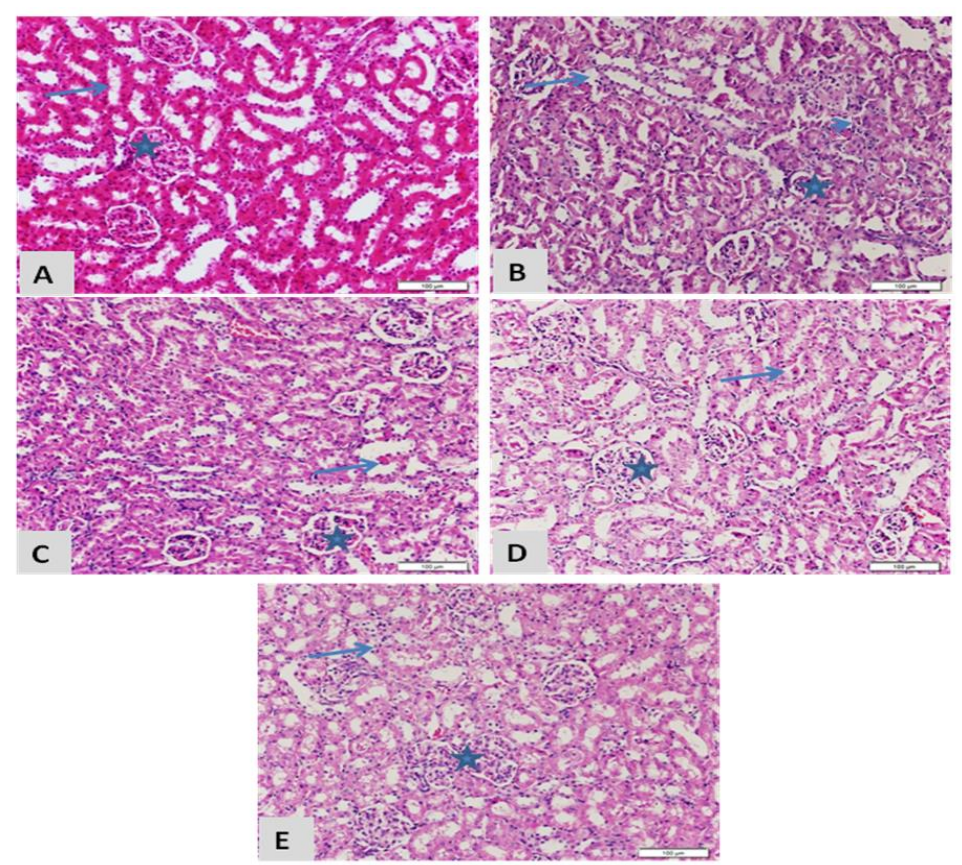

Figure 2 - Light photomicrographs from the kidney of rat stained with Hematoxylin and Eosin (Scale bar: $100 \mu \mathrm{m}$ ), in which (A), represent normal renal corpuscles (star) and renal tubules(arrow). (B) Section of rat kidney exposed to hypoxia, showing marked degeneration of many renal corpuscles (star) and degeneration of the epithelia of the tubules (arrow). Also, there are foci of cellular infiltration (arrow head). (C and D ) are sections of kidney from rats exposed to hypoxia and received arginine alone or carnosine alone respectively, showing a marked improvement of the renal corpuscles (star) and the tubules (arrow) and a marked decrease of the cellular infiltration. (E) Kidney of rat exposed to hypoxia and received a combination of arginine and carnosine, showing apparently normal histology of renal corpuscles (star) and tubules (arrow) and absence of cellular infiltration.

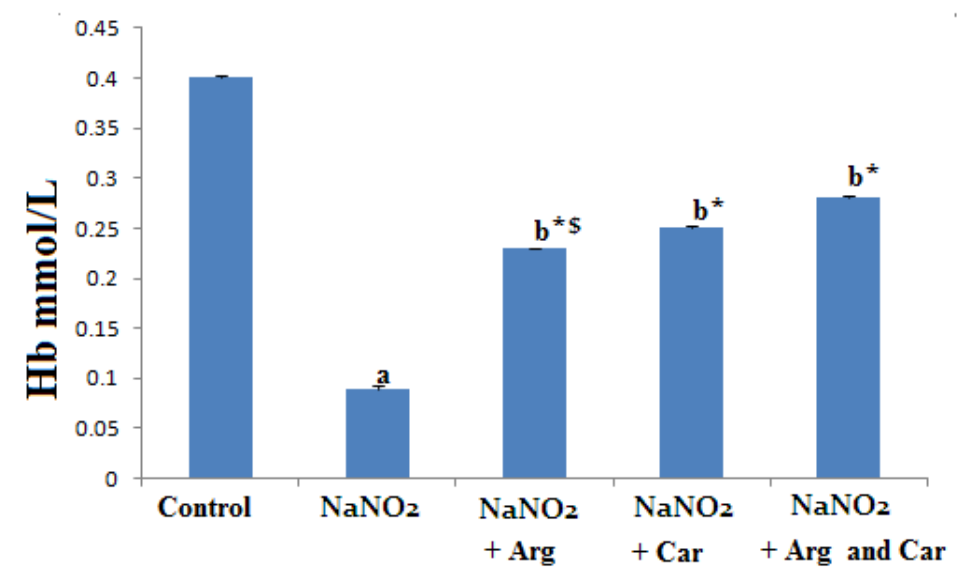

Figure 3- Effect of arginine (Arg) and/ or carnosine (Car) on blood $\mathrm{Hb}$ in control and $\mathrm{NaNO} 2$ induced hypoxia groups. Data are expressed as means \pm S.D $\quad(n=10) .{ }^{a} P \leq 0.001,{ }^{b} P \leq 0.01$, compared with the normal group, $* P \leq 0.001$, compared with $\mathrm{NaNO} 2$ induced hypoxia group, ${ }^{\$} P \leq 0.05$ compared with the combination group (NaNO2 + Arg $+\mathrm{Car}$ ), using ANOVA followed by Bonferroni as a post-ANOVA test 

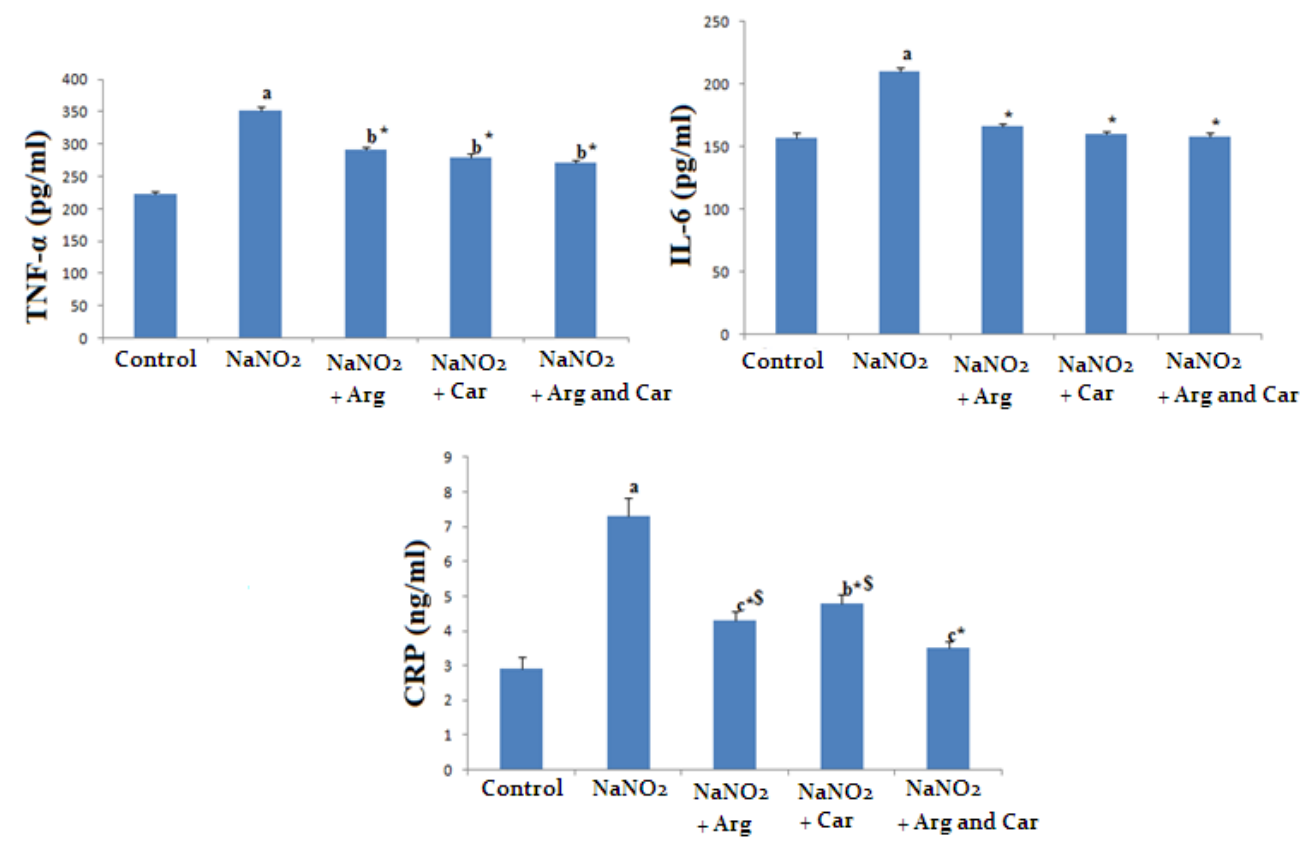

Figure 4 - Effect of arginine (Arg) and/ or carnosine (Car) on serum inflammatory markers (TNF- $\alpha$, IL-6 and CRP) in control and NaNO2 induced hypoxia groups. Data are expressed as means \pm S.D $(n=10)$. ${ }^{a} P \leq 0.001,{ }^{b} P \leq 0.01,{ }^{c} P \leq 0.05$ compared with the normal group, $* P \leq 0.001$, compared with NaNO2 induced hypoxia group, $\$ P \leq 0.05$ compared with combination group (NaNO2 + $\mathrm{Arg}+\mathrm{Car})$, using ANOVA followed by Bonferroni as a post-ANOVA test
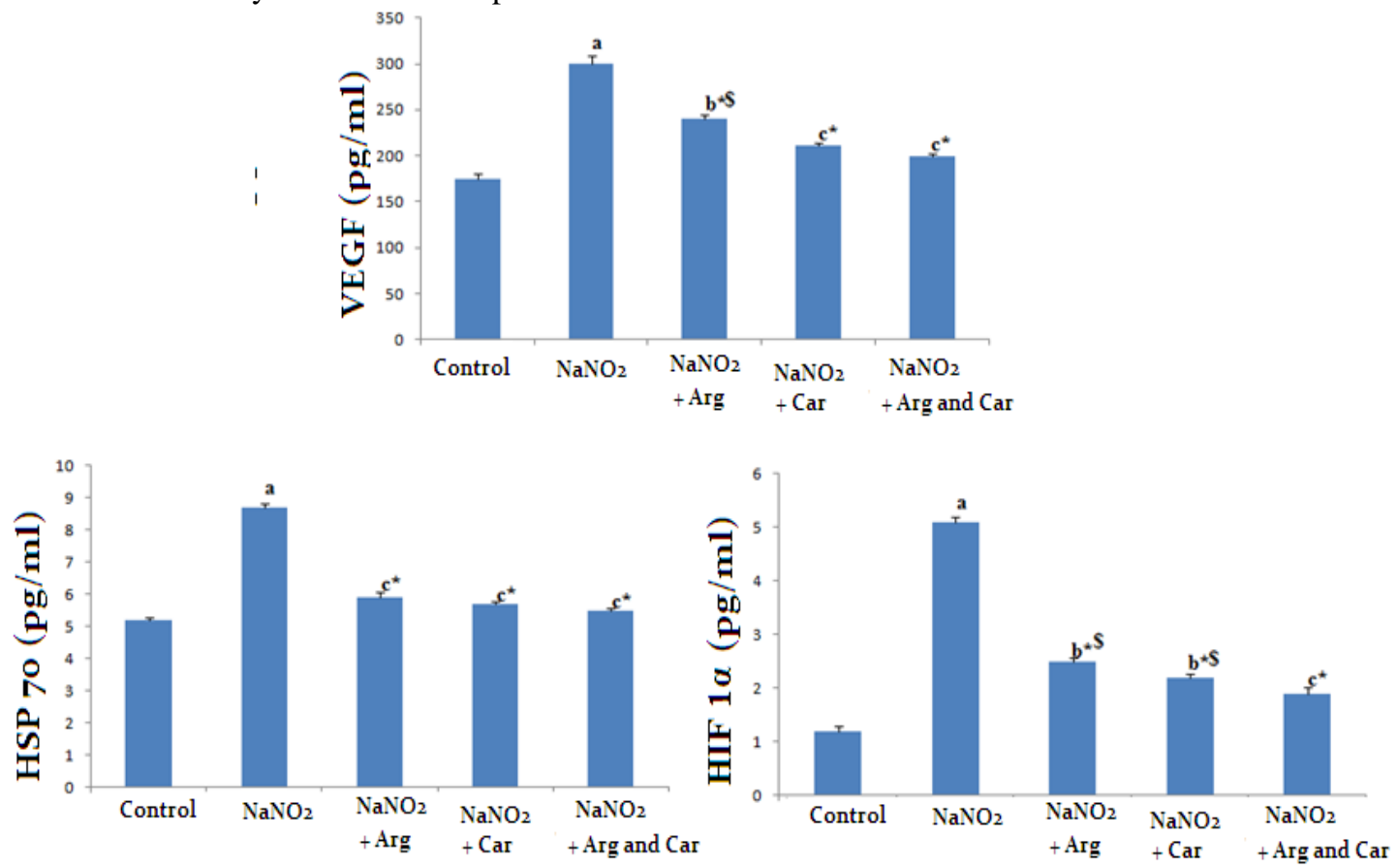

Figure 5- Effect of arginine (Arg) and/ or carnosine (Car) on serum VEGF, HSP70 and HIF1 $\alpha$ in control and NaNO2 induced hypoxia groups. Data are expressed as means \pm S.D $(\mathrm{n}=10) .{ }^{a} P \leq 0.001,{ }^{b} P \leq 0.01,,{ }^{c} P \leq 0.05$ compared with the control group, $* P \leq 0.001$, compared with $\mathrm{NaNO} 2$ induced hypoxia group, ${ }^{\$} P \leq 0.05$ 
compared with combination group (NaNO2 + Arg + Car ), using ANOVA followed by Bonferroni as a postANOVA test

\section{DISCUSSION}

Several studies have found that the deleterious impact of the hypoxia induced by $\mathrm{NaNO} 2$ is associated with oxidative stress, inflammation and methaemogobenemia which may have the principle role of organ damage and dysfunction , including renal damage (Hassan et al. 2009; El-Sheikh and Khalil 2011; Salama et al. 2013; Al-Gayyar et al. 2014).

In parallel with previous investigation, the current study revealed that induction of hypoxia in rats caused renal damage and dysfunction as indicated by the elevations in serum renal damage markers, namely creatinine and urea compared with control rats (Hassan et al., 2009). This result may indicate that exposure of renal tissue to hypoxia caused changes in the threshold of tubular re-absorption, renal blood flow and glomerular filtration rate. The deleterious impact of hypoxia induced by $\mathrm{NaNO} 2$ was further confirmed by the severely destructed renal tissue, as observed by the present histological examination which showed a marked degeneration of many renal corpuscles and epithelia of the tubules with foci of cellular infiltration. Administration of carnosine and/or arginine to hypoxic rats, significantly reduced the serum biomarkers of renal function compared with hypoxic untreated rats. This biochemical result was confirmed by histological observation which showed a marked improvement of the renal corpuscles and the tubules with a decrease in the cellular infiltration in rats pre-treated with either carnosine or arginine , however treatment of hypoxic rats with the combination of the two agents showed more or less normal histology of renal corpuscles and tubules with no cellular infiltration. This result may predict the beneficial synergistic protective impact of the combination of arginine and carnosine against renal damage induced by hypoxia. This beneficial effect of both carnosine and arginine was previously documented in animals that underwent experimental renal damage (Klahr 1999; Fujii et al. 2003 )

In line with previous studies, the present study demonstrated that induction of hypoxia in rats by $\mathrm{NaNO} 2$, caused a decrease in blood $\mathrm{Hb}$ level compared with normal animals (Gluhcheva et al 2012; Abu Aita \& Mohammed, 2014). This result may indicate the development of anemia in rats in response to hypoxia . The present decrease in $\mathrm{Hb}$ level may be attributed to a decrease in red blood cell count in response to NaNO2. Previous preliminary study declared a significant reduced red blood cell count in rats exposed to $\mathrm{NaNO} 2$ toxicity (Gluhcheva et al., 2012 ). Nitrite in toxic doses has been reported to induce hemic hypoxia. The underlying mechanism of such effect is mainly due to increased methemoglobin formation (Ger et al. 1996) .Some investigations reported that $\mathrm{NaNO} 2$ can induce oxidative damage and free radical generation that stimulates the oxidation of ferrous ions in oxyhemoglobin to form methemoglobin and erythrocyte lysis (Rahman et al. 2009; Abdel Baky et al. 2010) .

Administration of carnosine and/or arginine to hypoxic rats, significantly ameliorated the reduced level of blood $\mathrm{Hb}$ compared with the hypoxic untreated animals. The modulating effect of arginine and carnosine on blood $\mathrm{Hb}$ may contribute to their potential anti-oxidative stress due to antioxidant impacts as well as their free radical scavenging activity (Hartman et al. 1990; Giriş et al. 2014 ). Tarumoto et al. (2007) reported that L-arginine administration to anemic elderly patients suffering from renal disease, resulted in an increase in their hemoglobin level and improvement in their renal function. 
The present study also showed marked increases in the serum immunologic proinflammatory biomarkers, including TNF- $\alpha$, IL-6, and CRP, in hypoxic rats versus the control rats. The induction of such biomarkers may play a principle role in renal damage and dysfunction induced by hypoxia. Similar result has been obtained by some studies that revealed increases in inflammatory mediators, including TNF- $\alpha$ , IL-1 $\beta$, TGF- $\beta 1$ and CRP in rat livers and human adipose tissue in response to hypoxia (O'Rourke et al. 2011, Sherif and AlGayyar 2013; Al-Gayyar et al. 2014).

Pre-injection of carnosine and/or arginine to hypoxic rats, successfully attenuated the production of the inflammatory mediators, TNF- $\alpha$, IL- 6 , and CRP, suggesting that their reno-protective effect against the adverse impact of hypoxia. This beneficial impact of the two agents may be related to their anti-inflammatory and immunomodulatory beneficial actions. This result is confirmed by previous investigations, reporting that supplementation of either carnosine or Larginine could protect against the inflammatory responses caused by different pathological conditions by inhibiting the expression of these mediators (Huang et al. 2008; Lucotti et al. 2009; Tsai et al. 2010).

The present study showed a marked increase in the angiogenic index, VEGF, in the sera of hypoxic rats. Previous study declared that overproduction of inflammatory mediators induces VEGF expression by immune and inflammatory cells (Verheul et al. 2000; Lingen 2001). Overproduction of VEGF has been reported to be a major contributor in stimulating vasculogenesis and angiogenesis to restore oxygen supply to tissues during hypoxia (Ding et al 2004; Prior et al. 2004). On the other hand, some studies reported that TNF- $\alpha$ and VEGF up-regulation promote a procoagulant state by increasing expression of tissue factor on endothelial cells and/or monocytes (Clauss et al. 1996; Mechtcheriakova et al. 2001). Increased tissue factor expression is thought to play a significant role in the development of multiorgan system failure in acute injury (Mechtcheriakova et al. 2001). This may suggest that overproduction of TNF- $\alpha$ and VEGF in hypoxic rats, presented in the current study, act synergistically to promote renal dysfunction. Pre-administration of the studied agents alone or in a combination, significantly down-regulated the increase in VEGF in the sera of hypoxic rats, suggesting their beneficial anti-angiogenic potential action. This result is supported by some investigations which revealed the role of carnosine and arginine in reducing VEGF expression (Heffernan et al. 2006; Yeha et al.2010; Ali et al. 2015).

The current study also demonstrated a significant increase in the serum HSP-70 of hypoxic rats. The increased serum level of this protein may be related to its leakage out the tissue in response to tissue injury. HSPs are groups of intracellular proteins, classified, according to their molecular weight, into five groups, namely HSP27, HSP60, HSP70, HSP90, and HSP110. HSP60 (Joly et al. 2010) . Studies on HSPs have been shown that overexpression of the HSP gene is induced in response to environmental stress (Putnak and Schlesinger 1990; Schlesinger 1990). These proteins function as cytoprotectants, preserving cell survival by maintaining the vital functions of proteins among various cell types in pathological states (Oka et al. 2013; Li et al. 2013). They regulate the response to any detrimental factors, including temperature, radiation, hypoxia, toxins or infectious agents, by controlling the three-dimensional structure of the newly synthesized proteins, preventing their misfolding or degradation (Giffard et al. 2004). It was reported that HSP70 prominently induced after stress and has long been shown to contribute to cell survival in many pathological conditions (Thomas et al. 2002). Some authors have shown that Hsp70 can protect the tissues by inhibiting various inflammatory mediators (Zheng et al. 2008). However, cell 
Al-Rasheed, NM et al.

disintegration due to damage, or necrosis may evoke the early release of HSP outside the cell (Calderwood et al. 2007) . Extracellular HSP act as a danger signal to the system of the innate immunity (Matzinger 1994) . HSP can be recognized by antigen presenting cells (APC) and their interaction subsequently triggers APC to produce the proinflammatory cytokines and to activate the nuclear factor (NF)- $\kappa \mathrm{B}$, thus initiating the adaptive immune response and the presentation of antigens to the cytotoxic T cells (Srivastava 2002). HSP70 can also stimulate the production of proinflammatory cytokines (IL-6, TNF- $\alpha$ ) by monocytes and macrophages, as well as the expression of the adhesion molecules on the endothelial cells (Zhang et al. 2010) .

From the previous information, the present result may suggest that the increased level of serum HSP70 in hypoxic rats may have the major role in renal damage and dysfunction through inducing the overproduction of proinflammatory cytokines. Previous clinical study reported that the early release of HSP into the bloodstream after injury was associated with the development of severe tissue damage (Pespeni et al 2005) . Administration of carnosine and/or arginine to hypoxic rats, significantly reduced the serum HSP70 level . This study provides the first evidence that carnosine and arginine can reduce the endogenous cellular leakage of HSP70 into the blood stream, thus preventing its deleterious effects. This result may indicate the cytoprotective beneficial impact of these agents against hypoxia induced renal tissue injury. There is an evidence that carnosine and arginine can regulate intracellular HSP-70 expression which is essential for preventing organ dysfunction (Chatterjee et al. 2005; Mikami et al. 2006; Wu et al 2013) .

The current result also revealed that a marked elevation in the serum HIF- $1 \alpha$ of hypoxic rats compared with normal animals. Up-regulation of HIF- $1 \alpha$ in different models of acute renal injury was also documented (Rosenberger et al. 2002; 2003).

HIF-1 $\alpha$ is a transcription factor induced in response to hypoxic condition (Wenger et al., 2002). This transcription factor activates the expression of genes that are needed to maintain cellular homeostasis in the hypoxic state (Semenza et al. 2002). However, previous work postulated that induction of HIF-1 $\alpha$ in vivo is secondary to oxidative stress and inflammatory cytokines (Haddad \& Harb 2001; James et al. 2006) and its overexpression induces the expression of fibrogenic cytokines and collagen III in renal epithelial cell which play an important role in the pathogenesis of tubulointerstitial fibrosis (Basu et al. 2011). Administration of carnosine and/or arginine to hypoxic rats, significantly reduced the serum HIF-1 $\alpha$ level compared with the hypoxic untreated group. The ability of carnosine and /or arginine to suppress the production of HIF- $1 \alpha$ may correlate to their anti-inflammatory and anti-oxidant roles. Previous study found that carnosine could reduce the HIF-1 $\alpha$ stability and induced its proteasome degradation (Iovine et al. 2014). On the other hand, carnosine could act on HIF-1 $\alpha$ signaling, decreasing its protein level and consequently its transcriptional activity (Iovine et al. 2014). Also , experimental data demonstrated the ability of some other antioxidants to inhibit HIF-1 $\alpha$ expression (Gao et al. 2007) .

\section{CONCLUSION}

The present data showed that pretreatment with either L- arginine and/ or carnosine was beneficial in attenuating inflammation induced renal damage in response to $\mathrm{NaNO} 2$ induced hypoxia in rats . The combination of the two agents was the most effective one. This may support the use of this combination as an effective drug to prevent renal damage induced by hypoxic conditions.

Braz. Arch. Biol. Technol. v.59: e16150622 Jan/Dec 2016 


\section{ACKNOWLEDGEMENT}

This research was supported by a grant from the Research Center of the Center for Female Scientific and Medical Colleges, Deanship of Scientific Research, King Saud University.

\section{REFERENCES}

Abdel BNA, Zaidi ZF, Fatani AJ, et al. Nitric oxide pros and cons: The role of L-arginine, a nitric oxide precursor, and idebenone, a coenzyme-Q analogue in ameliorating cerebral hypoxia in rat. Brain Res Bull. 2010 ; 83(12):49-56.

Abu ANA, Mohammed FF . Effect of Marjoram Oil on the Clinicopathological, Cytogenetic and Histopathological Alterations Induced by Sodium Nitrite Toxicity in Rats. Global Veterinaria. 2014; 12 (5): 606-616.

Al-Gayyar MM, Al Youssef A, Sherif IO, et al. Protective effects of arjunolic acid against cardiac toxicity induced by oral sodium nitrite: effects on cytokine balance and apoptosis. Life Sci 2014; 111(1-2):18-26.

Al-Gayyar MM, Hassan HM, Alyoussef A, Abbas A, Darweish MM, El-Hawwary AA . Nigella sativa oil attenuates chronic nephrotoxicity induced by oral sodium nitrite: Effects on tissue fibrosis and apoptosis. Redox Rep 2015. (in press)

Ali SA, Rizk MZ, Abdelazim SA, et al. Role of potent antioxidants in regulation of SMAD-2 transcription and TGF-B1 signaling in nano sized titanium dioxide -induced oxidative injury in mice liver. Inter. J Pharmacotherapy 2015; 5(1): 17-26.

Ali SA, Aly HF, Faddah LM, Zaidi ZF . Dietary supplementation of some antioxidants against hypoxia. World J Gastroenterol 2012; 18(44): 6379-6386

Al-Rasheed N, Faddah L, Ibrahim H, Mohamed AM, Al-Rasheed N, Abdelbaky N . Role of Carnosine and Melatonin in Ameliorating Cardiotoxicity of Titanium Dioxide Nanoparticles in the Rats. Braz. Arch. Biol. Technol 2015; 58: 577-586.

Basu RK, Hubchak $\mathrm{S}$, Hayashida $\mathrm{T}$ et al. Interdependence of HIF-1a and TGF-b/Smad3 signaling in normoxic and hypoxic renal epithelial cell collagen expression. $A m \quad J$ Physiol Renal Physiol 2011; 300: F898-F905

Basuroy S, Bhattacharaya S, Tcheranova D, Qu Y, Regan RF, Leffler CW, Parfenova H. HO-2 provides endogenous protection against oxidative stress and apoptosis caused by TNF-a in cerebral vascular endothelial cells. Am J Physiol Cell Physiol 2006; 291:C897-C908

Bharadwaj LA, Davies GF, Xavier IJ, et al. 1Carnosine and verapamil inhibit hypoxiainduced expression of hypoxia inducible factor (HIF-1 alpha_) in H9c2 cardiomyoblasts. Pharmacol Res 2002; 45:175-181.

Bogdan C . Nitric oxide and the immune response. Nat Immunol 2001; 2:907-16

Bohle A. Mackensen-Haen S, Wehrmann M. Significance of postglomerular capillaries in the pathogenesis of chronic renal failure. Kidney Blood Press Res 1996; 19: 191-195.

Calderwood SK, Mambula SS, Gray PJ Jr . Extracellular heat shock proteins in cell signaling and immunity. Ann NY Acad Sci 2007; 1113:28-39.

Chatterjee S, Premachandran S, Sharma D, et al. Therapeutic treatment with L-arginine rescues mice from heat stroke induced death: physiological and molecular mechanisms. Shock 2005; 24(4):341-347.

Chung DH, Evers BM, TownsendCM . Role of polyamine biosynthesis during gut mucosal adaptation after burn injury. Am J Surg. 1993; 165:144-149

Clauss M, Grell M, Fangmann C, et al. . Synergistic induction of endothelial tissue factor by tumor necrosis factor and vascular endothelial growth factor: functional analysis of the tumor necrosis factor receptors. FEBS Lett 1996; 390:334-338

Craun GF, Greathouse DG, Gunderson DH . Methaemoglobin levels in young children consum-ing high nitrate well water in the United States. Int J Epidemiol 1981; 10:309317.

De Nadai C, Sestili P, Cantoni O, et al. . Nitric oxide inhibits tumor necrosis factor-alphainduced apoptosis by reducing the generation of ceramide. Proc Natl Acad Sci USA 2000; 97:5480-5.

Ding YH, LuanXD, Li J. Exercise-induced overexpression of angiogenic factors and reduction of ischemia/reperfusion injury in stroke. Curr Neurovasc Res 2004; 1(5):411420 . 


\section{Al-Rasheed, NM et al.}

Eckardt KU , Bernhardt WM, Weidemann A, Warnecke C, Rosenberger C, Wiesener MS, Willam C . Role of hypoxia in the pathogenesis of renal disease. Kidney Int Suppl. 2005; 99 :S46-51.

El-Sheikh NM, Khalil FA . L-Arginine and Lglutamine as immunonutrients and modulating agents for oxidative stress and toxicity induced by sodium nitrite in rats. Food Chem Toxicol 2011; 49(4):758-62.

Fujii T, Takaoka M, Muraoka T, Kurata $\mathrm{H}$ et al. Preventive effect of 1-carnosine on ischemia/ reperfusion-induced acute renal failure in rats. Eur J Pharmacol 2003; 474:261-267.

Gad MZ . Anti-aging effects of 1-arginine. JARE 2010; 1 : 169-177

Gao P, Zhang H, Dinavahi R, et al. HIFdependent antitumorigenic effect of antioxidants in vivo. Cancer Cell 2007; 12: 230-8.

Ger J, Kao H, . Shih TS, et al. (1996). Fatal toxic methemoglobinemia due to occupational exposure to methyl nitrite. Clin Med J 1996; $57:$ S78.

Giffard RG, Xu L, Zhao H, et al. Chaperones, protein aggregation, and brain protection from hypoxic/ischemic injury. J Exp Biol 2004; 207:3213-3220.

Giriş M, Doğru-Abbasoğlu S, Kumral A, et al. Effect of carnosine alone or combined with $\alpha$ tocopherol on hepatic steatosis and oxidative stress in fructose-induced insulin-resistant rats. J Physiol Biochem. 2014; 70(2):385-95.

Gluhcheva Y, Ivanovb I, Petrova E, et al. Sodium nitrite-induced hematological and hemorheological changes in rats. Series on Biomechanic 2012; 27: 53-58.

Go AS, Chertow GM, Fan D, McCulloch CE, Hsu CY. Chronic kidney disease and the risks of death, cardiovascular events, and hospitalization. N Engl J Med 2004; 351(13):1296-305.

Habermeyer M , Roth A, Guth S, Diel P, Engel KH, Epe B, Fürst P, Heinz V, et al. Nitrate and nitrite in the diet: how to assess their benefit and risk for human health. Mol Nutr Food Res. 2015; 59(1):106-28.

Haddad JJ, Harb HL . Cytokines and the regulation of hypoxia inducible factor (HIF)1alpha. Int Immunopharmacol 2001; 5: 46183.

Hartman PE, Hartman Z, Ault KT . Scavenging of singlet molecular oxygen by imidazole compounds: high and sustained activities of carboxy terminal histidine dipeptides and exceptional activity of imidazole-4-acetic acid. Photochem Photobiol 1990; 51:59-66.

Hassan HA, El-Agmy SM, Gaur RL, et al. In vivo evidence of hepato- and reno-protective effect of garlic oil against sodium nitriteinduced oxidative stress. Int J Biol Sci 2009; 5(3):249-255

Heffernan D, Dudley B, McNeil PL, et al. Local arginine supplementation results in sustained wound nitric oxide production and reductions in vascular endothelial growth factor expression and granulation tissue formation. J Surg Res 2006; 133:46-54

Huang CC, Tsai SC, Lin WT . Potential ergogenic effects of L-arginine against oxidative and inflammatory stress induced by acute exercise in aging rats. Exp Gerontol 2008; 43:571-577

Iovine B , Oliviero G, Garofalo M , et al. (2014). The anti-proliferative effect of L-carnosine correlates with a decreased expression of hypoxia inducible factor 1 alpha in human colon cancer cells. PLoS One 2014; 9(5):e96755.

Ivanov V, Cha J, Ivanova S, et al. Essential nutrients suppress inflammation by modulating key inflammatory gene expression. Int $\mathrm{J}$ Mol Med 2008; 22:731-741

James LP, Donahower B, Burke AS, et al. Induction of the nuclear factor HIF-1alpha in acetaminophen toxicity: evidence for oxidative stress. Biochem Biophys Res Commun 2006; 43:171-6.

Joly AL, Wettstein G, Mignot G, et al. Dual role of heat shock proteins as regulators of apoptosis and innate immunity. J Innate Immun 2010; 2:238-247

Klahr S . Can 1-arginine manipulation, reduce renal disease? Semin Nephrol 1999; 19(3):304-9.

Kiliś-Pstrusińska K . Carnosine, carnosinase and kidney diseases. Postepy Hig Med Dosw 2012; 66:215-21.

Kjeldsberg CR . Principles of hematologic examination. In: Wintrobe's clinical hematology, vol.1. Lee G.R.; Bittell, T.C.; Foerster, J.; Athens, J.W. and Lukens, J.N. (eds.).Philadelphia, London 1993; pp. 7-37.

Li L, Han ZY, Li CM, et al. Upregulation of heat shock protein 32 in Sertoli cells alleviates the impairments caused by heat shock-induced apoptosis in mouse testis. Cell Stress Chaperones 2013; 18:333-351. 
Lingen MW . Role of leukocytes and endothelial cells in the development of angiogenesis in inflammation and wound healing. Arch Pathol Lab Med 2001; 125:67-71

Lucotti P, Monti L, Setola E, et al. Oral Larginine supplementation improves endothelial function and ameliorates insulin sensitivity and inflammation in cardiopathic nondiabetic patients after an aortocoronary bypass. Metabolism Clin Exp 2009; 58:1270-1276

Matzinger P (1994). Tolerance, danger, and the extended family. Annu Rev Immunol 1994; 12:991-1045

Mechtcheriakova D, Schabbauer G, Lucerna M, et al. Specificity, diversity, and convergence in VEGF and TNF-alpha signaling events leading to tissue factor up-regulation via EGR1 in endothelial cells. FASEB J 2001; 15:230 242

Mikami K, Otaka M, Watanabe D, et al. Zinc Lcarnosine protects against mucosal injury in portal hypertensive gastropathy through induction of heat shock protein 72 . J Gastroenterol Hepatol 2006; 21:1669-1674.

Morimoto R I, Tissieres A, Georgopoulous C . The stress response, function of the proteins, and perspectives. In Morimoto, R. I., Tissieres, A., and Georgopoulous, C. (eds.), Stress Proteins in Biology and Medicine, Cold Spring Harbor Press, New York 1990; pp. 1-37.

Moinard C, Cynober L, de Bandt JP . Polyamines: metabolism and implications in human diseases. Clin Nutr 2005; 24:184-197

Morris Jr SM . Arginine: beyond protein. Am $J$ Clin Nutr 2006; 83(2):508S-12S.

Oka Y, Akagi Y, Kinugasa T, et al. Heat-shock pre-treatment reduces liver injury and aids liver recovery after partial hepatectomy in mice. Anticancer Res 2013; 33:2887-2894.

O'Rourke RW, White AE, Metcalf MD, Olivas AS, Mitra P, Larison WG, Cheang EC, Varlamov O, Corless CL, Roberts CT Jr, Marks DL . Hypoxia-induced inflammatory cytokine secretion in human adipose tissue stromovascular cells. Diabetologia 2011; 54(6):1480-90.

Pespeni M, Mackersie RC, Lee H, et al . Serum levels of HSP 60 correlate with the development of acute lung injury after trauma. J Surg Res 2005; 126:41.

Prior BM, Yang HT, Terjung RL . What makes vessels grow with exercise training? J Appl Physiol 2004; 97(3):1119-1128.
Putnak J R, Schlesinger JJ . Protection of mice against yellow fever virus encephalitis by immunization with a vaccinia virus recombinant encoding the yellow fever virus non-structural proteins, NS1, NS2a and NS2b. J Gen Virol 1990; 71:1697-1702.

Rahman M M, Kim S J, Kim G B, et al. Nitriteinduced methemoglobinaemia affects blood ionized and total magnesium level by hydrolysis of plasma adenosine triphosphate in rat. Basic Clin Pharmacol Toxicol. 2009; 105(5):294-300.

Remuzzi G, Bertani T. Pathophysiology of progressive nephropathies. N Engl J Med. 1998 339(20):1448-1456.

Rius J, Guma M, Schachtrup C, et al. NFkappaB links innate immunity to the hypoxic response through transcriptional regulation of HIF-1alpha. Nature. 2008; 453:807-811.

Rosenberger C, Mandriota S, Jurgensen JS, et al. Expression of hypoxia-inducible factor-1alpha and -2alpha in hypoxic and ischemic rat kidneys. J Am Soc Nephrol 2002; 13: 17211732.

Rosenberger C, Griethe W, Gruber G, et al. (2003) Cellular responses to hypoxia after renal segmental infarction. Kidney Int 2003; 64: 874-886.

Salama MF, Abbas A, Darweish MM, et al. Hepatoprotective effects of cod liver oil against sodium nitrite toxicity in rats. Pharm Biol 2013; 51(11):1435-43.

Schlesinger MJ . Heat shock proteins. J Biol Chem 1990; 265:12111-12114.

Semenza G . Signal transduction to hypoxiainducible factor 1. Biochem Pharmacol 2002; 64:993-8.

Sherif IO, Al-Gayyar MM . Antioxidant, antiinflammatory and hepatoprotective effects of silymarin on hepatic dysfunction induced by sodium nitrite. Eur Cytokine Netw 2013; 24(3):114-21.

Srivastava $\mathrm{P}$. Interaction of heat shock proteins with peptides and antigen presenting cells: chaperoning of the innate and adaptive immune responses. Annu Rev Immunol 2002; 20:395425

Stvolinsky S, Kukley M, Dobrota D, et al. . Carnosine protects rats under global ischemia. Brain Res Bull 2000; 53:445-448.

Tarumoto T, Imagawa S, Kobayashi M, et al. 1Arginine administration reverses anemia associated with renal disease, Int $J$ Hematol 2007; 86 : 126-129.

Braz. Arch. Biol. Technol. v.59: e16150622 Jan/Dec 2016 
Al-Rasheed, NM et al.

Thomas G, Souil E, Richard MJ, et al. . Hyperthermia assists survival of astrocytes from oxidativemediated necrotic cell death. Cell Mol Biol (Noisy-le-grand) 2002; 48:191198.

Tsai SJ1, Kuo WW, Liu WH, et al. Antioxidative and anti-inflammatory protection from carnosine in the striatum of MPTP-treated mice. J Agric Food Chem 2010; 58(21):11510-6.

Tong M, Longato L, de la Monte SM . Early limited nitrosamine exposures exacerbate high fat diet-mediated type 2 diabetes and neurodegeneration. BMC Endocr Disord. 2010; 10:4

Verheul HM, Jorna AS, Hoekman K, et al. Vascular endothelial growth factor-stimulated endothelial cells promote adhesion and activation of platelets. Blood 2000; 96:42164221

Wenger RH . Cellular adaptation to hypoxia: O2sensing protein hydroxylases, hypoxiainducible transcription factors, and $\mathrm{O} 2$ regulated gene expression. FASEB J 2002; $16: 1151-62$
Wu GH, Zhang YW, Wu ZH . Modulation of postoperative immune and inflammatory response by immuneenhancing enteral diet in gastrointestinal cancer patients. World $J$ Gastroenterol 2001; 7:357-362

Wu X, Xie C, Yin Y, et al. Effect of Larginine on HSP70 expression in liver in weanling piglets. BMC Veterinary Research 2013, 9:63

Yeha CL, Paib MH, Lic CC, et al. Effect of arginine on angiogenesis induced by human colon cancer: in vitro and in vivo studies. $J$ Nutr Biochem 2010; 21:538-543

Zhang X, Xu Z, Zhou L, et al. Plasma levels of Hsp70 and anti- Hsp70 antibody predict risk of acute coronary syndrome. Cell Stress Chaperones 2010; 15:675-686

Zheng Z, Kim JY, Ma H, et al. Antiinflammatory effects of the $70 \mathrm{kDa}$ heat shock protein in experimental stroke. J Cereb Blood Flow Metab 2008; 28:53-63.
Received: October 13, 2015; Accepted: January 11, 2016. 


\title{
Erratum
}

In the 01 page, that read:

\author{
"Nouf M. Al-Rasheed" ${ }^{1}$, Laila Fadda1 , Azza M Mohamed*2,3, Hala A. Attia ${ }^{1}$, Nawal \\ M. Al-Rasheed ${ }^{1}$ \\ ${ }^{1}$ Department of Pharmacology, King Saud University, Riyadh, Saudi Arabia. ${ }^{2}$ Biochemistry Department, \\ Faculty of Science, King Abdulaziz University, Jeddah, Saudi Arabia. ${ }^{3}$ Theraputic Chemistry Department, \\ National Research Center, Dokki, Egypt."
}

Read:

"Nouf M. Al-Rasheed ${ }^{1}$, Laila Fadda ${ }^{1}$, Azza M Mohamed*2,3, Hala A. Attia ${ }^{1,4}$, Nawal M. Al-Rasheed ${ }^{1}$

${ }^{1}$ Department of Pharmacology and Toxicology, College of Pharmacy, King Saud University, Riyadh, Kingdom of Saudi Arabia. ${ }^{2}$ Biochemistry Department, Faculty of Science - Al Faisaliah, King Abdulaziz University, Jeddah, Saudi Arabia. ${ }^{3}$ Theraputic Chemistry Department, National Research Center, Dokki, Egypt. ${ }^{4}$ Department of Biochemistry, College of Pharmacy, Mansoura Univrsity, Mansoura, Egypt." 